\title{
On the possible pyrochlore to aurivillius phase transition in the complex oxide $\mathrm{CaCd}_{2} \mathrm{Bi}_{2} \mathrm{Nb}_{4} \mathrm{O}_{15}$
}

\author{
M.L. Craus, I. Rusu ${ }^{1}$, A. Rusu ${ }^{1}$ and N. Apostolescu ${ }^{1}$ \\ Institute for Technical Physics, Bd. Dimitrie Mangeron 47, lasi 6600, Romania \\ 1 Technical University Gh. Asachi, Faculty of Industrial Chemistry, Bd. Dimitrie Mangeron 71, \\ lasi 6600, Romania
}

\begin{abstract}
The sample $\mathrm{CaCd}_{2} \mathrm{Bi}_{2} \mathrm{Nb}_{4} \mathrm{O}_{15}$ was synthesised by the standard ceramic method, starting from a mixture of oxides heated up to $1250^{\circ} \mathrm{C}$. The chemical composition indicate that the oxide could have an Aurivillius or a substituted pyrochlore structure. The X-ray diffraction and IR spectra suggest a phase transition from pyrochlore, at $-196^{\circ} \mathrm{C}$, to Aurivillius at room temperature. The DSC analyses performed in the temperature range $20-400^{\circ} \mathrm{C}$ did not evidenced major phase transitions for the material.
\end{abstract}

\section{INTRODUCTION}

Previous studies performed on the pseudo-quaternary system $\mathrm{CaO}-\mathrm{CdO}-\mathrm{Bi}_{2} \mathrm{O}_{3}-\mathrm{Nb}_{2} \mathrm{O}_{5}$ led to the synthesis and identification of a series of compounds with possible Aurivillius type structures $\left(\mathrm{A}_{n-1} \mathrm{Bi}_{2} \mathrm{~B}_{\mathrm{n}} \mathrm{O}_{3 \mathrm{n}+3}\right)$ [1, 2]. Subsequent researches confirmed the Aurivillius structure for some of these members $[3,4]$. The aim of the present paper is to study the structure, the possible phase transitions, at low temperatures and the thermal stability up to $1350^{\circ} \mathrm{C}$ for the oxide with the following gravimetric composition: $2.56 \% \mathrm{Ca}-16.7 \% \mathrm{Cd}-32.08 \% \mathrm{Bi}-29.1 \% \mathrm{Nb}-\mathrm{O}$.

\section{EXPERIMENTAL}

The synthesis, based on the ceramic technology, has been described in our previous paper [2]. The chemical analyses were performed by means of a Carlo Erba EA 1108 elemental analyser and did not evidence the presence of carbonate or hydroxyl groups in the final sample. The cation ratio was determined by means of EPMA. The samples were also studied by X-ray diffraction, using a low temperature chamber, cooled with liquid nitrogen, and two kinds of radiation $(\mathrm{MoK} \alpha, \mathrm{CoK} \alpha)$. We have also determined the melting point of the compound $\left(1350^{\circ} \mathrm{C}\right)$. After cooling the samples were submitted again to the X-ray diffraction analysis, in order to determine the phase composition. The IR spectrum was recorded using a Specord M80 spectrophotometer in the frequency range $300-1000 \mathrm{~cm}^{-1}$, the powder sample being mixed with $\mathrm{KBr}$ and pressed as pellets. The magnetic susceptibilities were measured with a Sherwood Scientific balance that was calibrated with $\mathrm{Hg}\left[\mathrm{Co}(\mathrm{NCS})_{4}\right]$. The $\mathrm{DSC}$ curve was recorded by means of a Mettler Toledo $12 \mathrm{E}$ microcalorimeter, using aluminium crucibles, at a heating rate of $20^{\circ} \mathrm{C} / \mathrm{min}$, up to $400^{\circ} \mathrm{C}$. The evaluation of the thermal effects (with a precision of $\pm 0,01 \mathrm{~J} / \mathrm{g}$ ) and of the temperature (with a precision of $\pm 0,1^{\circ} \mathrm{C}$ ) was achieved using a TA89A V 4.00 software. 


\section{RESULTS AND DISCUSSION}

The chemical composition can be assigned to both a substituted pyrochlore of formula [5]: $(\mathrm{Ca}, \mathrm{Cd})_{2-\mathrm{x}} \mathrm{Bi}_{\mathrm{x}}[\mathrm{Nb},(\mathrm{Ca}, \mathrm{Cd}) / \mathrm{Bi}]_{2} \mathrm{O}_{7}$, or to an Aurivillius type structure with $\mathrm{n}=4$.

The EPMA analyses evidenced the presence of some small amounts of $\mathrm{CaNb}_{2} \mathrm{O}_{6}$ and $\mathrm{BiNbO}_{4}$ as secondary phases. The X-ray diffraction studies also revealed the presence of these secondary phases, evaluated to less than $10 \%$ of the total amount. The diffraction data have been processed using TREOR software [6]. The searching range for the unit cell volume, used to index the spectrum, was based on the ratio between the molar weight and the picnometeric density. A selection of the obtained results was made on the basis of the merit figure, calculated accordingly to the literature [7]. The Miller indices are listed in Table 1.

Table 1. The interplanar distances for the mixed oxide $\mathrm{CaCd}_{2} \mathrm{Bi}_{2} \mathrm{Nb}_{4} \mathrm{O}_{15}$

\begin{tabular}{|c|c|c|c|c|c|}
\hline \multicolumn{2}{|c|}{$T_{t}=1350^{\circ} \mathrm{C}(\operatorname{CoK} \alpha)$} & \multicolumn{2}{|c|}{$T_{\text {meas }}=20^{\circ} \mathrm{C}$} & \multicolumn{2}{|c|}{$T_{\text {meas }}=-196^{\circ} \mathrm{C}$} \\
\hline d & hkl & d & hkl & d & hkl \\
\hline 12.130 & 200 & & & & \\
\hline 3.226 & 021 & & & & \\
\hline 3.198 & 121 & & & & \\
\hline 3.152 & 302 & & & & \\
\hline 3.074 & 112 & & & 3.041 & 004 \\
\hline \multirow[t]{2}{*}{3.003} & 212 & 3.008 & 020 & & \\
\hline & & 2.694 & 220 & & \\
\hline 2.606 & 811 & 2.605 & 202 & 2.545 & 400 \\
\hline 2.496 & 022 & & & 2.495 & 401 \\
\hline 2.389 & 230 & 2.391 & 212 & & \\
\hline \multirow[t]{2}{*}{2.148} & 431 & 2.130 & & 2.154 & 403 \\
\hline & & 2.083 & 022 & 2.108 & 413 \\
\hline \multirow[t]{11}{*}{1.999} & 631 & & & & \\
\hline & & & & 1.892 & 520 \\
\hline & & 1.851 & 322 & 1.868 & 521 \\
\hline & & 1.773 & 512 & & \\
\hline & & 1.579 & 522 & 1.585 & 406 \\
\hline & & 1.514 & 800 & & \\
\hline & & 1.370 & 341 & 1.312 & 704 \\
\hline & & 1.201 & 921 & 1.214 & 803 \\
\hline & & 1.173 & 151 & & \\
\hline & & 1.090 & 714 & 1.079 & 850 \\
\hline & & 1.042 & 932 & 1.054 & 914 \\
\hline \multicolumn{2}{|c|}{$\begin{array}{l}a=24.436 ; b=7.309 ; \\
c=6.840 \AA ; M=11\end{array}$} & \multicolumn{2}{|c|}{$\begin{array}{c}a=12.107 ; b=6.019 ; \\
c=5.774 \AA ; M=14\end{array}$} & \multicolumn{2}{|c|}{$\begin{array}{l}a=10.183 ; b=10.183 \\
c=12.152 \AA ; M=7\end{array}$} \\
\hline
\end{tabular}

The X-ray density changed as a function of the measurement temperature and of the applied thermal treatment.

The samples analysed at room temperature were indexed as orthorhombic structures. The sample sintered and slowly cooled with the furnace from the sintering temperature have a Aurivillius structure, with one molecule per the unit cell, whereas the sample cooled from the melting temperature have the same kind of structure with four molecules per the unit cell.

On the other hand, the sample analysed at $-196^{\circ} \mathrm{C}$ has a tetragonal structure, similar to a distorted pyrochlore (see Table 1 and Figure 1). An increase of the theoretical density (about 25\%) has been observed with the temperature decrease. In order to get supplementary information regarding the 
structure, we have tried to assume an Aurivillius unit cell to this sample. The calculations of the unit cell performed on the basis of the previously obtained Miller indices by the analysis at room temperature, infirm the possibility of having an Aurivillius superstructure. The thermodynamic calculations presented in the literature [8] indicate that the layered perovskites to pyrochlore phase transition is accompanied by heat release. That could be in agreement with possible existence of a stable pyrochlore phase at low temperatures.
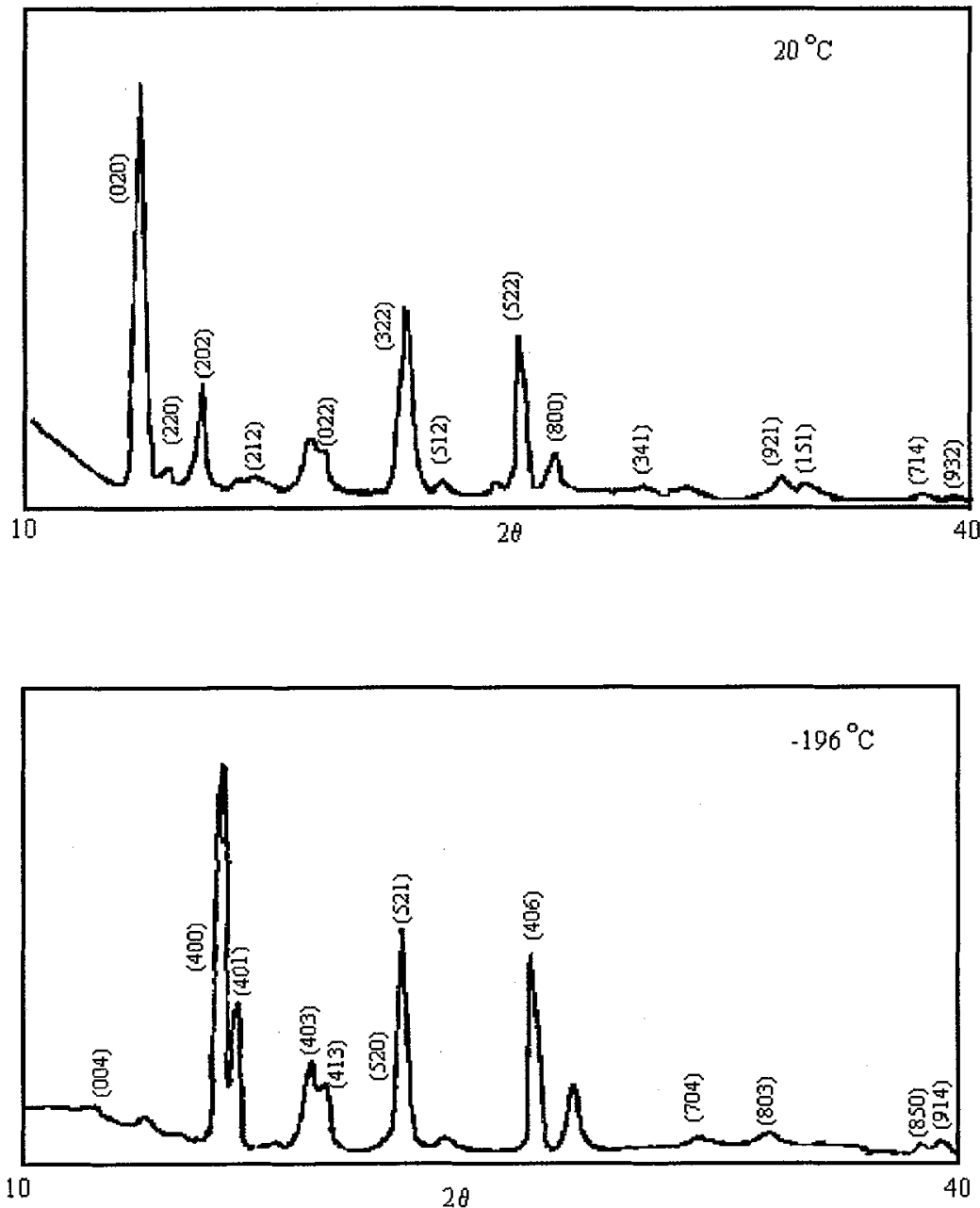

Figure 1. The X-ray diffraction spectra of the mixed oxide at room temperature and in liquid nitrogen

The IR spectrum of the compound $\mathrm{CaCd}_{2} \mathrm{Bi}_{2} \mathrm{Nb}_{4} \mathrm{O}_{15}$ (see Figure 2) is similar with that of the term $\mathrm{n}=5$ [3], fact that suggests according to literature the presence of a layered perovskite structure [9]. The bands appearing in the frequency range $300-500 \mathrm{~cm}^{-1}$ may be assigned both to the $\mathrm{NbO}_{6}$ octahedrons and to the vibration of $\mathrm{BiO}_{n}$ polyhedrons. Obviously the $\mathrm{BiO}_{n}$ polyhedrons do not possess octahedral symmetry; IR studies on bismuth containing oxides evidenced the presence of $\mathrm{BiO}_{n}$ pyramids, fact that justifies the Aurivillius structure [10]. The bands from 500 to $1000 \mathrm{~cm}^{-1}$ are assigned only to the stretching and bending of $\mathrm{NbO}_{6}$ octahedrons, if we consider a layered perovskite structure. 
The magnetic measurements evidenced a low paramagnetism $\left(\chi_{\mathfrak{g}}=1.2256 \cdot 10^{-7}\right)$ indicating the possible existence of the niobium cations into an oxidation state lower than (5t). This is in agreement with the chemical formula of the Aurivillius structure. Otherwise, the stoichiometry imposed by the existence of only di- and pentavalent cations, excepting the bismuth, would give improbable the existence of the term $\mathrm{n}=4$ for the Aurivillius structure. We have to mention that the literature presents superior terms of Aurivillius structure based on niobium oxide only by the substitution of a part of the niobium cations with other cations having lower oxidation states [11].

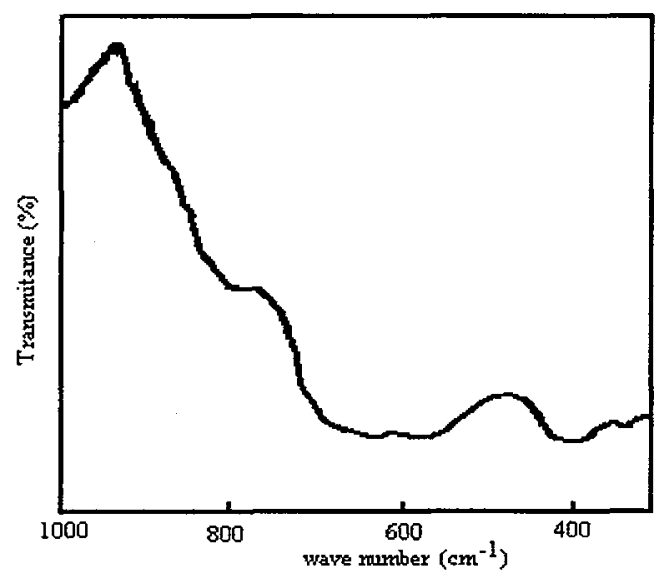

Figure 2. The IR spectrum of the mixed oxide $\mathrm{CaCd}_{2} \mathrm{Bi}_{2} \mathrm{Nb}_{4} \mathrm{O}_{15}$

The DSC curve presents three very small endothermic effects $(\mathrm{J} / \mathrm{g})$ in the following temperature regions $\left({ }^{\circ} \mathrm{C}\right): 1.33 /(48.7-72.8), 0.09 /(195.7-205.8)$ and $0.01 /(315.9-323.6)$. The first peak, which is the largest, is not associated with any change in the sample's mass. Therefore, we may say that the thermal analysis did show any major phase transition, in air, up to $400^{\circ} \mathrm{C}$.

\section{CONCLUSION}

In the pseudo-quaternary system $\mathrm{CaO}-\mathrm{CdO}-\mathrm{Bi}_{2} \mathrm{O}_{3}-\mathrm{Nb}_{2} \mathrm{O}_{5}$, we have found the synthesis possibility of superior Aurivillius terms.

At low temperature a phase transition from an Aurivillius to a pyrochlore structure could be observed. The Aurivillius phase is observable at room temperature, while at low temperatures the pyrochlore type phase seems to be more stable.

The compound melts congruently, the diffraction data suggesting the presence of a superstructure at high temperature.

The results regarding the positions of the atoms in the unit cell, implicitly the relative intensities of the diffraction maximums, will be published somewhere else.

\section{References}

[1] Rusu I., Oxide compounds with special properties (Doctoral Thesis, Technical University "Gheorghe Asachi" Iasi, 1998) pp.53-61.

[2] Rusu I., Craus M.-L., Bull. IPI, Chemistry and Chemical Engineering 3-4 (2000), in print

[3] Rusu I., Craus M.-L., Rosca I., Condliffe E., Smith M.J., Sutiman D., Palamaru M., Cailean A. and Apostolescu N., "Information regarding the structure of a new complex oxide based on $\mathrm{Ca}$, 
$\mathrm{Cd}, \mathrm{Bi}$ and $\mathrm{Nb}$ from dielectric measurements. Aurivillius or pyrochlore?", $10^{\text {th }}$ International Symposium on Electrets, Delphi 22 - 24 September 1999, A.A. Konsta, A. Vassilikou-Dova, K. Vartzeli-Nikaki Eds. (IEEE, Piscataway NJ, 1999) pp. 325-328.

[4] Craus M.-L, Rusu I., Rosca I., Rusu A. and Nechita M., Annals of "Aurel Vlaicu" University of Arad, Chemistry 1 (2000) 339-342

[5] Istomin S.Y., D'yachenko O.G., Antipov E.V. and Svensson G., Mat. Res. Bull. 32 (1997) 421-429.

[6] Werner P.-E., Z.Krist. 120 (1964) 375-387.

[7] De Wolff P.M., J.Appl.Cryst. 1 (1968) 108-113.

[8] Reznitskii L.A., Inorganic Materials 32 (1996) 397-402.

[9] Ratheesh R., Sreemoolanadhan H. and Sebastian M.T., J. Solid State Chem. 131 (1997) 2 - 8

[10] Dimitriev Y., "Glass formation and structure of non-traditional oxide glasses", The First Balkan Conference on Glass Science \& Technology, Volos 9-100 October 2000, G. Kordas and N.S. Vlachos Eds. (University of Thessaly, 2000) pp.34 - 43.

[11] Yu W.J., Kim Y.I., Ha D.H., Lee J.H., Park Y.K., Seong S. and Hur N.H., Solid State Commun. 111 (1999) 705-709. 